MANChester, R.C. (1945) Chronic haemolytic anaemia with paroxysmal nocturnal haemoglobinuria. Ann. intern. Med. 23, 935.

MARKS, J. (1949) The Marchiafava Micheli syndrome. Quart. J. Med. 18, 105.

Nussey, A.M. \& Dawson, D.W. (1956) Paroxysmal nocturnal haemoglobinuria. Case study, including evidence of affection of the marrow in the disease. Blood, 11, 757.

ScotT, R.B., Roвb-Smith, A.H.T. \& Scowen, E.F. (1938) The Marchiafava-Micheli syndrome of nocturnal haemoglobinuria with haemolytic anaemia. Quart. J. Med. 8, 95 .

Wolman, L. (1956) Pituitary necrosis in raised intracrania pressure. J. Path. Bact. 72, 575.

\title{
Adult hypertrophic pyloric stenosis
}

\author{
N. A. M. SAlmo \\ Ph.D.(Manchester) \\ Department of Pathology \\ Faculty of Medicine, University of Mosul, Mosul, Iraq
}

HYPERTROPHY of the muscle fibres of the pylorus in the adult is a curious lesion that deserves more frequent consideration, especially in the differential diagnosis of constricting lesions of the distal stomach. Although male predominance is not as marked in adult as in infantile hypertrophic pyloric stenosis, men exceed women in the ratio of $3: 1$ (Andresen, Gammelgaard \& Licht, 1946; North \& Johnson, 1950). The great majority of adults presenting with symptoms referable to pyloric muscle hypertrophy are between 30 and 60 years of age. The age range, however, is wide; some symptomatic cases have been observed in patients in the ninth decade of life (Albot \& Magnier, 1955).

The present report describes a case of hypertrophic pyloric stenosis in a young female, adding one to the small number recorded.

\section{Case report}

An unmarried female aged 15 years was admitted to the Republican Hospital on 7 September 1966 complaining of vomiting of 6 months' duration. The vomiting was at first mild and sparse, later it became frequent and copious. It was unrelated to the type of food. The vomitus was invariably sour in taste and contained undigested food particles. There was no history of haematemesis or melaena. There had been some weight loss.

On admission she appeared slightly wasted but not acutely ill. No abnormalities were found in the heart, lungs, abdomen, urinary system and the central nervous system. The liver and spleen were not palpable. Her temperature was $36.8^{\circ} \mathrm{C}$, the blood pressure was $110 / 70 \mathrm{mmHg}$ and the pulse was $90 / \mathrm{min}$.
Investigations. $\mathrm{Hb} 11.8 \mathrm{~g} / 100 \mathrm{ml}$, ESR $53 \mathrm{~mm} / \mathrm{hr}$ (Westergren); WBC $7650 / \mathrm{mm}^{3}$ with a normal differential count. The stool contained no occult blood. Chest radiograph was normal.

The patient received chlorpromazine, ferrous sulphate and vitamin B complex daily for 12 days with no benefit. On barium meal examination (Fig. 1) the stomach was found dilated and ptosed; the duodenal cap was not visualized in all the projections; no barium distal to the gastric antrum could be detected; hypertrophy of the gastric mucosal pattern was noted. The findings were in favour of a long-standing pyloric obstruction. In view of this, the patient was transferred to the surgical side on 20 September 1966 for operation. Pre-operatively she received iron intramuscularly, vitamin B complex and vitamin $C$. The operation was performed on 9 October 1966.

Operation. The stomach was exposed through an upper median incision extending down to the umbilicus. It was found to be greatly dilated and there was no evidence of ulceration. The viscera were normal. A soft mass was felt in the pyloric region and a small incision was made through it. A villouslike obstruction was found in the pyloric canal, the lumen of which measured no more than a few millimeters in diameter. A localized partial gastrectomy with gastro-duodenostomy was performed. The regional sub-pyloric lymph nodes were removed and were sent with the excised pylorus for histopathological examination.

The post-operative course was uneventful. At follow-up, the patient showed a moderate gain in weight, good appetite and no dyspeptic symptoms. A post-operative barium meal showed a normal- 


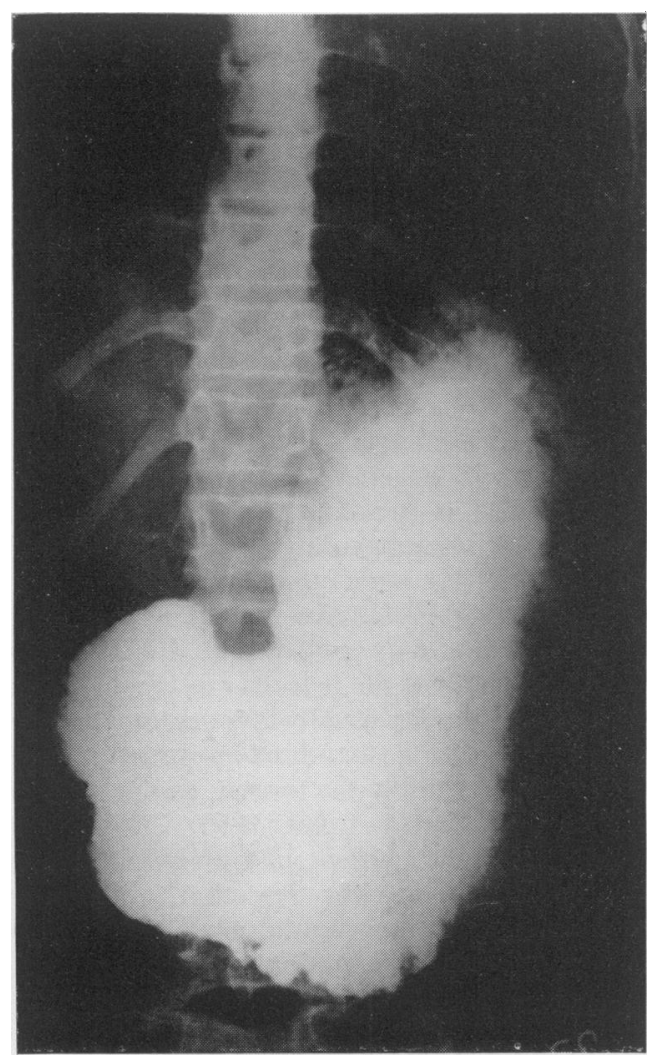

FIG. 1. Radiograph showing dilatation and ptosis found in the stomach on barium meal examination.

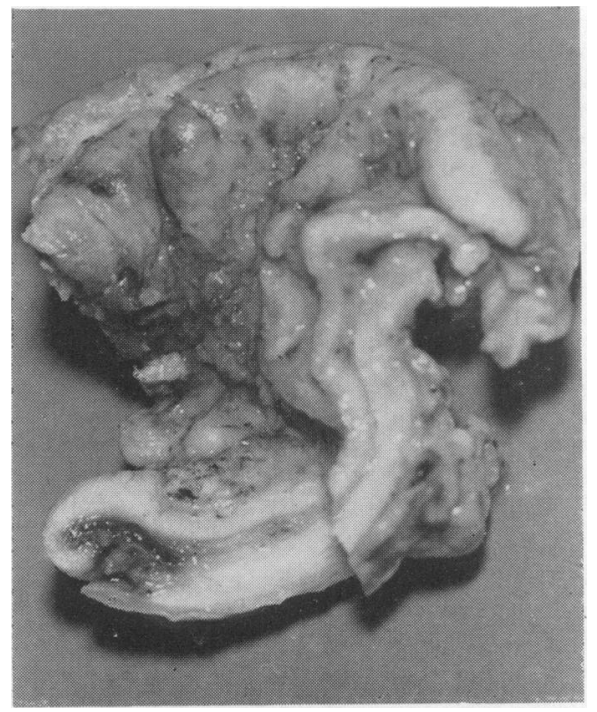

Fig. 2. The excised pylorus showing a moderate thickening of its wall.

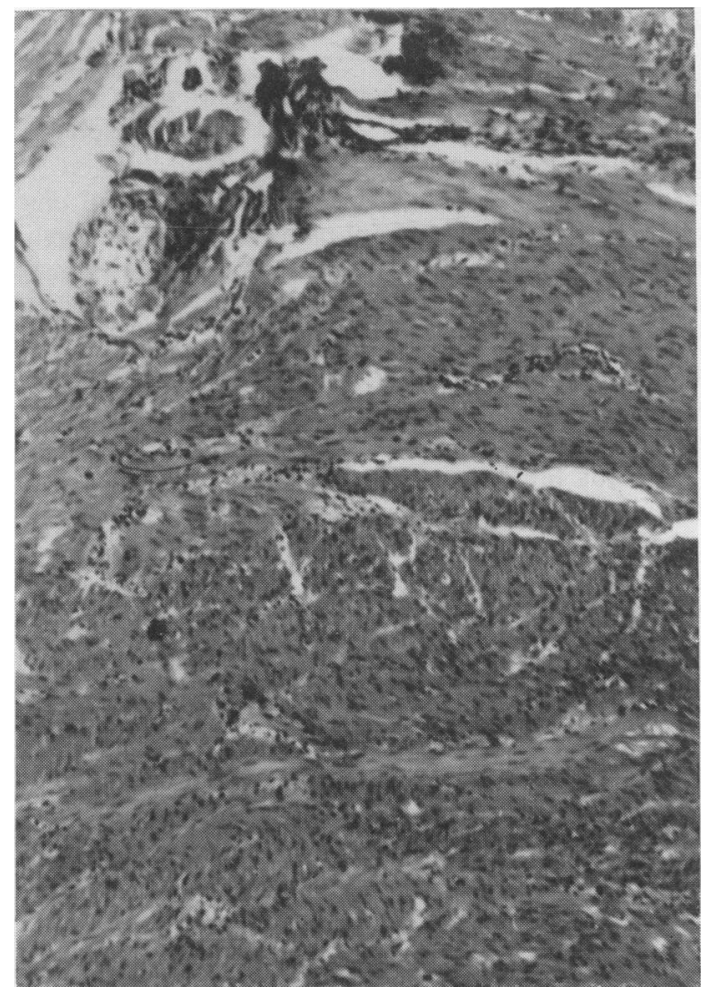

FIG. 3. Microscopical section of the wall showing thickness which appeared to be due, principally, to hypertrophy of the circular muscle fibres which are seen to run in all directions.

sized stomach; the barium was homogeneously distributed all over the stomach; the duodenal cap was not visualized in all the projections; the barium passed freely into the duodenum; the gastric antrum and the pylorus were missing; evacuation time of the barium was normal.

Pathological findings. Gross inspection of the excised pylorus showed a moderate thickening of its wall (Fig. 2). The thickness varied from 8 to $20 \mathrm{~mm}$ with an average of $11 \mathrm{~mm}$. Microscopically the thickness appeared to be due principally to hypertrophy of the circular muscle fibres which were seen to run in all directions (Fig. 3). The submucosa was thickened and fibrotic and contained abundant ectatic blood vessels. Inflammatory cells were rather scanty, but some areas showed occasional lymphocytes. The mucosa was considerably thick and fronded and contained a scattering of inflammatory cells. Histology of the sub-pyloric lymph nodes showed evidence of non-caseating chronic granuloma compatible with sarcoid tissue. 


\section{Discussion}

Primary pyloric muscle hypertrophy would appear to be highly uncommon in adults judged from the few reported cases. Andresen, Gammelgaard \& Licht, in a review published in 1946, tabulated 167 cases reported from 1885 to 1940 and added eight of their own. North and Johnson, however, reporting in 1950 , considered that only sixty-four acceptable adult cases of pyloric muscle hypertrophy without associated gastric abnormalities had been reported to that date. Berk (1963) reported twenty cases of pyloric muscle hypertrophy in adults from 1945 to 1963; another was added in 1964.

Various factors were thought to cause this condition. Of the many hypotheses, the following have attracted the greatest interest; antral gastritis (Albot \& Magnier, 1953; Konjetzny, 1933; Golden, 1937; Prinz, 1939; Zettergren, 1949; Berg, 1952), pyloric ulcer (Horwitz, Alvarez \& Ascanio, 1929), obstructing duodenal ulcer and pyloric carcinoma (Horwitz et al., 1929; Stout, 1943; Kreel \& Ellis, 1965). The occurrence of pyloric obstruction in these conditions would probably have to be considered as a secondary change and not as a primary disease. A high gastric ulcer or prolonged pylorospasm may lead to hypertrophy of the pyloric muscle (Coleman, 1932; Craver, 1957; Keet, 1958). Much rarer lesions producing pyloric narrowing include eosinophilic gastroenteritis which is associated with changes in the small intestine (Wolf \& Khilnani, 1966). Our case did not show any of these lesions and it is possible, therefore, to regard the pyloric hypertrophy as a result of persistence of the infantile hypertrophic pyloric stenosis. This hypothesis has many supporters who consider the adult type of pyloric stenosis to result either from persistence of the mechanisms responsible for the congenital lesion, or from failure of the infantile changes to regress. Usually, symptoms are present from infancy. Out patient and her relatives denied any previous history of gastric disturbances. It is possible that the pyloric hypertrophy was present at birth, but that the lesion remained dormant until certain secondary factors such as gastritis or spasm supervened (Skoryna, Dolan \& Clay, 1959).

The histological appearances also support this view. It has been postulated that the lesion in the adult is basically similar to that in the infant, exhibiting the same changes in the circular muscle of the pylorus and the pyloric myenteric ganglion cells and plexuses (Belding \& Kernohan, 1953; Raia et al., 1956). It has also been suggested that the numerous ectatic, angiomatous-like vessels commonly noted in the submucosa of adults with pyloric muscle hypertrophy may be of congenital origin (Wallensten, 1952). Our case exhibited thickening of the submucous coat which contained many dilated blood vessels. This finding agrees with Wallensten's hypothesis of the congenital origin of pyloric hypertrophy in adults. Gastric sarcoidosis may present with pyloric narrowing (McNulty, 1967). However, in our case, this lesion of the subpyloric lymph nodes is, in our opinion, a coincidental finding since no similar lesion was found in the pyloric muscle wall.

The diagnosis of this condition can only be established with certainty by operation and microscopic examination (Berk, 1964). If the pylorus is recognizably thickened and no other lesion can be identified, any one of a number of different procedures may be employed. Pyloromyotomy may be performed as is commonly done in infants. It is possible with this procedure, however, to miss a neoplasm. Gastrojejunostomy also has the disadvantage of overlooking some other lesion in the pylorus. Pyloroplasty of the Heineke-Mikulicz type may be done. This, too, may not reveal another lesion situated in an area of the pylorus not included in the biopsy. Opinion today usually favours limited gastric resection with either gastro-duodenostomy or gastrojejunostomy, preferably the former, as the treatment of choice (McCann \& Dean, 1950; Craver, 1957; Knight, 1961). Our patient had an excellent result following limited gastric resection and gastroduodenostomy and was asymptomatic for over one year. She refused investigations for sarcoidosis.

\section{Acknowledgment}

Our thanks are due to Dr K. Shabander for his help and criticism.

\section{References}

Albot, G. \& Magnier, F. (1953) L'hypertrophie musculaire du pylore de l'adulte (forme myomareuse de l'atresie fibromusculaire de l'antre). Arch. mal. appl. digest. 42, 347.

Andresen, K., GammelgaARd, A. \& Licht, E. DE Fr. (1946) Hypertrophy of the pylorus in adults. Acta Radiol. 27, 552.

BeldiNG, H.H., III \& KERNOHAN, J.W. (1953) A morphologic study of the myenteric plexuses and musculature of the pylorus with special reference to the changes in hypertrophic pyloric stenosis. Surg. Gynec. Obstet. 97, 322.

BERG, H.M. (1952) Antral gastritis. Radiology, 59, 324.

BERK, J.E. (1963) Gastroenterology (Ed. by H. L. Bockus), Vol. 1, pp. 875. Saunders, Philadelphia.

Berk, J.E. (1964) Pyloric muscle hypertrophy in the adult. J. Int. Coll. Surg. 41, 1.

Coleman, M. (1932) Hypertrophic pyloric stenosis in adults. Lancet, ii, 892.

Craver, W.L. (1957) Hypertrophic pyloric stenosis in adults. Gastroenterology, 33, 914.

Golden, R. (1937) Antral gastritis and spasm. J. Amer. med. Ass. 109, 1497.

Horwitz, A., Alvarez, W.C. \& Ascanio, H. (1929) The normal thickness of the pyloric muscle and the influence on it of ulcer, gastroenterostomy and carcinoma. Ann. Surg. 89, 521.

KeET, A.D., JR (1958) The prepyloric contractions in certain abnormal conditions. Acta Radiol. 50, 413.

KNIGHT, C.D. (1961) Hypertrophic pyloric stenosis in the adult. Ann. Surg. 153, 889. 
Konjetzny, G.E. (1933) Zur Gastritis frage. Wien. klin. Wschr. 46, 451.

Kreel, L. \& Ellis, H. (1965) Pyloric stenosis in adults. A clinical and radiological study of 100 consecutive patients. Gut, 6, 253.

McCann, J.C. \& Dean, M.A. (1950). Hypertrophy of the pyloric muscle in adult; experience with conservative and radical surgical treatment. Surg. Gynec. Obst. 90, 535.

McNulty, J.G. (1967) Adenomyoma of stomach. Brit. med. J. 3, 843.

North, J.P. \& Johnson, J.H., Jr (1950) Pyloric hypertrophy in adult. Ann. Surg. 131, 316.

Prinz, H. (1939) Zur frage der Pylorushypertrophie des Erwachsenen unter besonderer des Berucksichtigung bestimmter Formen Pfortnerkrebses. Arch. klin. Chir. $197,1$.
Raia, A., Curti, P., de Almeida, A.C. \& Fry, W. (1956) The pathogenesis of hypertrophic stenosis of the pylorus in the new born and the adult. Surg. Gynec. Obst. 102, 705.

Skoryna, S.C., Dolan, A.S. \& Clay, A. (1959) Development of primary pyloric hypertrophy in adults in relation to the structure and function of the pyloric canal. Surg. Gynec. Obst. 108, 83.

Stout, A.P. (1943) Pathology of carcinoma of the stomach. Arch. Surg. 46, 807.

WAllensten, S. (1952) Pyloric hypertrophy in adults. Acta chir. scand. 104, 285.

Wolf, B.S. \& KhILNANI, M.T. (1966) Progress in gastroenterological radiology. Gastroenterology, 51, 542.

ZetTERGReN, L. (1949) Does any genetic connection exist between pyloric hypertrophy in infants and adult? Acta chir. scand. 97, 533.

\title{
Seat-belt fracture of the tibia
}

\author{
J. M. PEGUM* \\ M.A., M.D.(Dublin), F.R.C.S.I. \\ Senior House Officer in Orthopaedic Surgery, \\ St Peter's Hospital, Chertsey, Surrey
}

INJURIES involving car seat-belts are usually due to the force with which the car occupant is thrown against the belt in a collision. Various patterns of injury have been described. Injury to the lumbar spine or abdominal wall and contents is due to flexion of the spine over, or compression of the abdomen by, a lapbelt, producing the 'seat-belt syndrome' (Garrett \& Braunstein, 1962). Fractures of the ribs and sternum may be produced by a diagonal belt (Fletcher \& Brogden, 1967). Injuries to the face and neck, produced when a car-occupant wearing a lap-belt is thrown forward to dash his face on the facia or windscreen, are not due to the pressure of the belt, but the pattern of injury is determined by its action (Lancet, 1967).

Although the seat-belts contributed to the injuries in such cases, it is generally accepted that the collisions in which they occurred would have produced far more serious injuries but for the restraining action of the belts (Bourke, 1965). Even a lap-belt alone reduces the chance of serious injury by a factor as high as 30 (Lancet, 1967). Various reviews have found no case in which a seat-belt has actually caused severe injury, or increased the severity of the injuries (Lindgren \& Warg, 1962; Gissane, 1963; Brit. med. J., 1964).

The case described here, in which no injury would have occurred but for the belt, is reported because

* Present address: Bedford General Hospital, Kempston Road, Bedford. it draws attention to a real and easily-avoided danger from seat-belts.

\section{Case history}

The patient was a 24-year-old woman, 7 months pregnant with her first child. She was a front-seat passenger in a car fitted with lap-strap and diagonal seat-belts which, when not in use, lay loose on the floor of the car. In getting out of the car she inadvertently put her left foot through a loop of the belt, which tightened round her leg a few inches above the ankle. This tripped her, so that she fell to the ground outside the car, with her left leg still caught in the belt.

She sustained a short spiral fracture of the left tibia 3-4 in. above the ankle, with a comminuted spiral fracture of the fibula at a slightly lower level (Fig. 1). The fracture was open from within, the end of the upper tibial fragment protruding through a wound about 2 in. long. Surgical toilet of the wound was performed under general anaesthetic, and balanced traction was applied to a Denham pin inserted through the left calcaneum.

Seventeen days after the injury an above-knee plaster cast was applied, and she was allowed up on crutches, but not bearing weight on the injured leg. Seven weeks after injury the plaster cast was changed from above-knee to below-knee type, to facilitate delivery, and 14 days later she was delivered, the 